\title{
Analysis of design parameters of pistons and piston rings of a combustion engine
}

\author{
Grzegorz Koszalka ${ }^{1, *}$, and Andrzej Suchecki ${ }^{2}$ \\ ${ }^{1}$ Lublin University of Technology, Faculty of Mechanical Engineering, ul. Nadbystrzycka 36, 20-618 Lublin, Poland \\ ${ }^{2}$ Automotive Research and Development Institute BOSMAL, ul Sarni Stok 93, 43-300, Bielsko-Biała, Poland
}

\begin{abstract}
This paper analyzes the effect of gaps in the lock of the first and second sealing rings and selected dimensions of the ring belt of the piston on the piston-ring-cylinder seal. The research was performed using a mathematical model of the seal system. Simulation results have shown that a significant reduction in the exhaust gas flow to the crankcase - without compromising other parameters characterizing the performance of the seal - would require increased production rigor. Reducing the blow-by without the need to narrow the tolerance intervals of the engine components is possible, but this would be accompanied by increased reverse gas flow from the inter-ring space towards the combustion chamber. The research has also shown that the ring seal of the automotive compression ignition engine, which was the starting point for testing, was optimized for minimizing gas flow towards the combustion chamber at the expense of increased flow of exhaust gases to the crankcase.
\end{abstract}

\section{Introduction}

The choice of dimensions for the ring part of the piston and of the piston rings that determine the size of the clearance between the rings, the piston and the cylinder is crucial to the proper functioning of the ring pack of an internal combustion engine. Due to the various functions the sealing system must fulfil and the variable working conditions, optimization of this system is difficult. Dimensions that cause a lower exhaust gas flow rate are not the most advantageous in terms of oil consumption, or resistance to motion and engine durability [1]. Therefore, it is necessary to seek compromise solutions. Improving the piston-ring-cylinder (PRC) structure only via empirical research is very expensive and does not always produce satisfactory results. This is due to the high cost of producing samples and the large number of variants to examine, as well as difficulties with regard to the assessment of changes made to the engine. Assessed parameters such as blow-by, quantitative engine oil consumption, exhaust gas pollutant concentrations, mechanical losses, etc. are characterized by low measurement repeatability, and taking into account the relatively small expected changes resulting from structural changes made to the system, obtaining reliable results requires extended testing, ideally carried out on multiple units of the test engine. Therefore, in design work mathematical modeling is employed. Currently, advanced models allow testing of other structural parameters on the PRC under different engine operating conditions [2-12].

Several mechanisms for the transport of engine oil towards the combustion chamber are mentioned in the literature: entrainment in the form of oil mist together with gases flowing through the seal of the PRC towards the combustion chamber; oil scrapping through the piston rings towards the combustion chamber; oil throwing due to inertial effects in the vicinity of TDC. The oil entering the combustion chamber leads to increased concentrations of hydrocarbons and particulate in the exhaust gas [1, 12-15].

Some researches point out that the oil entrainment in the form of oil mist with the gases flowing in the direction of the combustion chamber may be the main cause of oil consumption [16-17]. To limit return flows, efforts are made (inter alia) to reduce the pressure in the gap between the first and second compression rings. These actions can, however, cause increased blow-by.

Many modern engines are characterisied by relatively large flows of exhaust gas into the crankcase (blow-by). The engine that was the starting point for the results presented in this work had the following blow-by: at maximum torque more than $30 \mathrm{dm}^{3} / \mathrm{min}$ per $\mathrm{dm}^{3}$ of the engine's swept volume (in terms of power $1 \mathrm{dm}^{3} / \mathrm{min} / \mathrm{kW}$ ) and at maximum power: $20 \mathrm{dm}^{3} / \mathrm{min} / \mathrm{dm}^{3}$ and $0.5 \mathrm{dm}^{3} / \mathrm{min} / \mathrm{kW}$, respectively [18].

The existence of this relatively large blow-by was the motivation for undertaking research with the aim of evaluating the engine design solutions adopted. This paper is limited to the assessment of the impact of selected dimensions of the ring part of the piston and the clearance in the compression ring locks on the blow-by and the intensity of the reverse gas flowing from the ring seal towards the combustion chamber (blow-up).

* Corresponding author: g.koszalka@pollub.pl 


\section{Research object and methods}

\subsection{Research object}

The research engine was a 4-cylinder, turbocharged diesel engine with a displacement of $1.3 \mathrm{dm}^{3}$ with intake air cooling and exhaust gas recirculation. According to its technical specifications, the maximum power of the engine is $55 \mathrm{~kW}$, obtained at $4000 \mathrm{rpm}$ and the maximum torque is $190 \mathrm{Nm}$ at $1750 \mathrm{rpm}$. The engine has 4 valves per cylinder and a Common Rail injection system with direct fuel injection. The engine has a cast iron block with cylinders of nominal diameter $69.6 \mathrm{~mm}$; the stroke of the piston is $82 \mathrm{~mm}$. The aluminum pistons have a cast iron insert under the first compression ring. The ring seal consists of three rings: firstly a rectangular compression ring with a chrome-plated barrel face surface; secondly a tapered compression ring; and a double-lipped oil ring with a chromium-plated face surface and a helical spring. Nominal gaps in the ring locks are: first compression ring $-0.25 \mathrm{~mm}$, second compression ring $-1.25 \mathrm{~mm}$ and oil ring $-0.375 \mathrm{~mm}$.

\subsection{Mathematical model}

The mathematical model of PRC sealing presented in [19] was used for the simulation studies. This model is an integrated model of gas flow through the apertures of the PRC system, displacement and twisting of the rings in the piston grooves and the oil film between the rings and the cylinder liner. The calculations presented in this study do not take ring twisting into account and the oil film sub-model was not employed; frictional forces between the rings and the cylinder were calculated from empirical correlations (see [19]).

The input data for the calculations were determined on the basis of the engine's documentation, MES calculation (thermal deformation of the piston and the rings) and actual measurements (combustion chamber pressure). Calculation of the cylinder liner's thermal deformation was taken into account, but it was simplified to assume that the diameter of the deformed liner was constant over its entire height.

\subsection{Simulation testing}

The dimensions of the clearance in the locks of the compression rings and the dimensions of the piston shown in Fig. 1 were varied in the execution of the simulations. The influence of these dimensions on the blow-by and blow-up, as well as the axial displacement of the rings in the grooves and the pressure in the interring spaces (output values) were assessed.

In the first step, the impact of each dimension on the output values was evaluated, with the other dimensions remaining unaltered. In the second phase, taking into account the results obtained in the first stage, the effect of simultaneous changes of several dimensions on the performance of the sealing system was assessed. In the simulation individual dimensions varied over a wide range - but remained within the limits of realistic implementation.

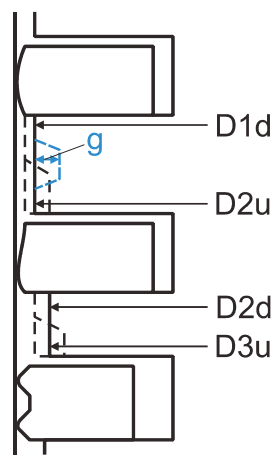

Fig. 1. Dimensions of the piston used as variables in the simulation tests.

\section{Results and discussion}

\subsection{Impact of selected dimensions on PRC sealing}

The effects of the clearance in the lock of the first and second compression rings on blow-by and by-up under rated conditions (full load at $4000 \mathrm{rpm}$ ) are shown in Figures 2 and 3. In the figures the larger symbols show the values corresponding to the starting dimensions, based on the documentation provided by the engine manufacturer. As expected, reducing the clearance in the locks causes the blow-by to decrease, with the effect of the clearance in the lock of the first ring being much larger than the clearance in the second ring. Reducing the clearance in the lock of the first ring also reduces blow-up, while reducing the clearance in the lock of the second ring results in very high increase in the rate of blow-up. The reason of this increase in the blow-up is the increase in pressure in the space between the first and second rings caused by the reduction of the clearance in the second ring lock (Fig. 4). The pressure increase in the first inter-ring space above the pressure in the combustion chamber forces the gas flow from this space towards the combustion chamber.

Pressure changes in the inter-ring spaces also affect the displacement of the rings within the grooves. With low clearance values in the lock of the second ring, the first compression ring changes its axial position in the groove during the compression stroke and at the end of the power stroke (Fig. 5). It is considered that displacement in these strokes of the cycle is unfavorable and may lead to so-called collapse of the ring, which is accompanied by a near-complete loss of its gas-tightness $[4,20]$. In turn, higher values of the pressure in the first inter-ring space may positively affect the displacement of the second ring. At certain values of these pressures (as for second ring clearance equal to $0.25 \mathrm{~mm}$, hence the same as the clearance of the first ring in the engine design), the second ring does not move at all and during the entire engine work cycle it is adjacent to the lower edge of the groove (Fig. 5). 


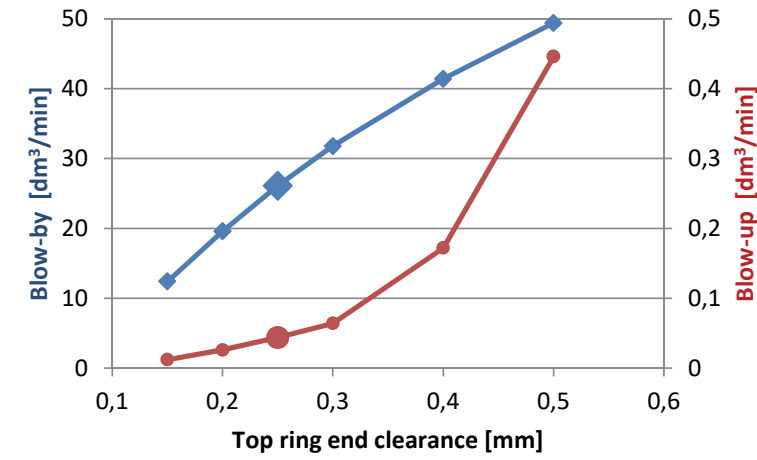

Fig. 2. The influence of the clearance in the lock of the first compression ring on the blow-by and blow-up.

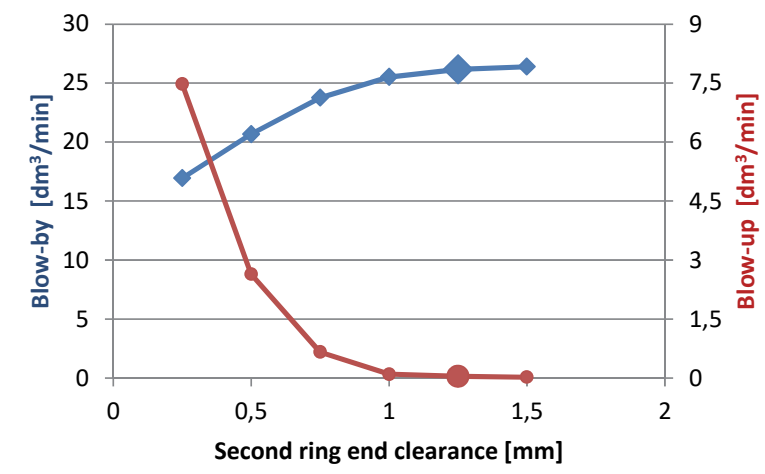

Fig. 3. The effect of the clearance in the lock of the second compression ring on the blow-by and blow-up.

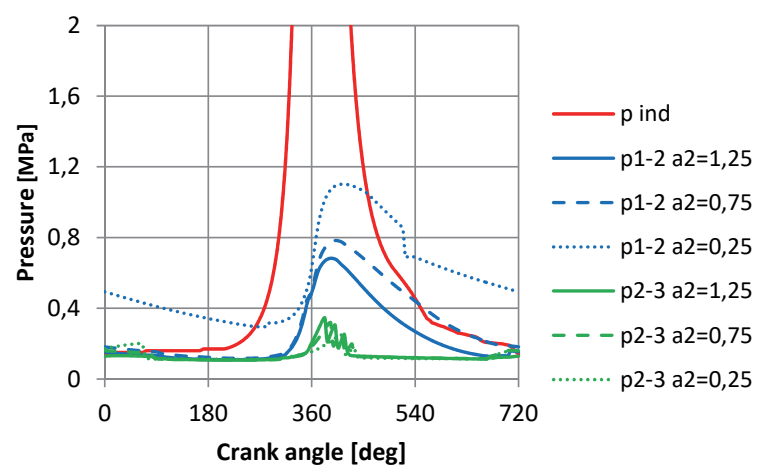

Fig. 4. Impact of clearance in the lock of the second compression ring on pressure in the inter-ring spaces.

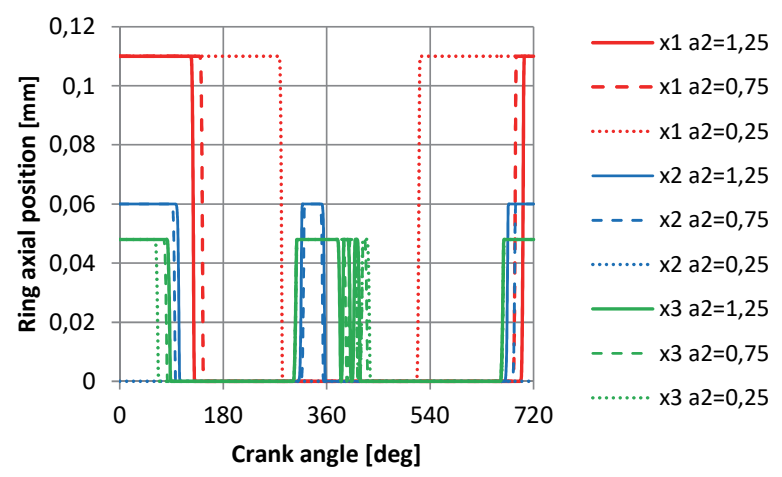

Fig. 5. Impact of clearance in the lock of the second compression ring on the axial displacements of the rings in the grooves.
The diameters of the piston in the vicinity of the ring grooves determine the cross-sectional areas through which the gas can flow through the ring locks. Their impact on the gas flow is therefore somewhat similar to the impact of the clearances in the ring locks. The greater the diameter of the piston under the first groove $D 1 d$, the lower the blow-by and blow-up (Fig. 6). Increasing the diameter of the piston under the second groove $D 2 d$ also reduces the blow-by, but much less than in the case of $D 1 d$. Unfortunately, increasing this diameter is highly detrimental to blow-up (Fig. 7).

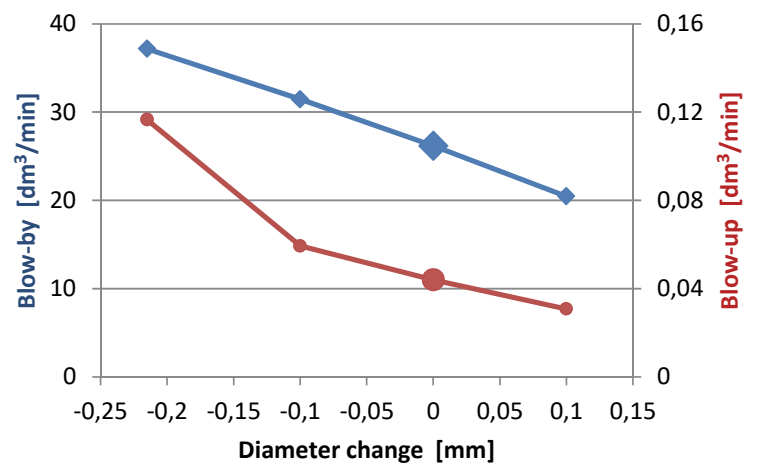

Fig. 6. Influence of piston diameter under the first compression ring $D 1 d$ on the blow-by and blow-up.

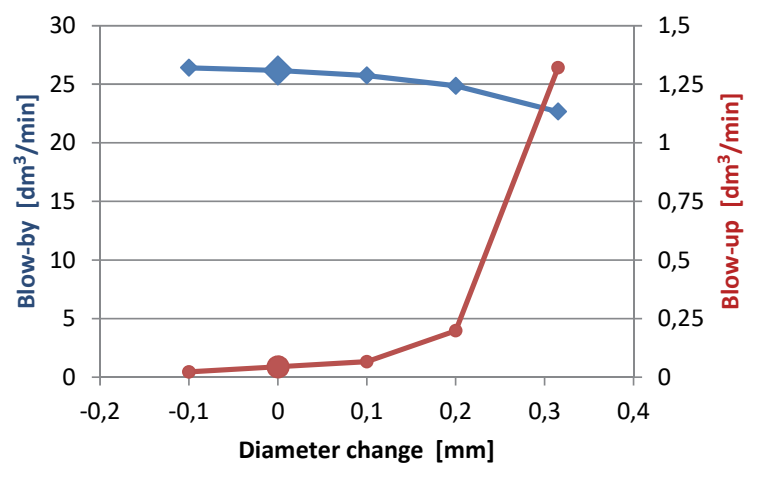

Fig. 7. Influence of piston diameter under the second compression ring $D 2 d$ on the blow-by and blow-up.

The diameter of the piston over the second groove $D 2 u$ has a significant effect on the volume of the first inter-ring space, and hence on the pressure at that location. On the other hand, it affects the active cross section of the gas flow through the lock of the second ring when it is adjacent to the upper flank of the groove. The combined effect of these factors - despite the significant changes in the pressure in the inter-ring space and in the displacement of the second ring (Fig. 9) makes the impact of this diameter on blow-by and blowup relatively small and non-monotonic (Fig. 8).

The effect of using an additional groove made in the inter-ring space to increase the accumulative capacity of this space was also simulated (see blue line in Fig. 1; such an approach is sometimes used in engines, especially larger ones). Increasing this volume results in a reduction of the maximum pressure in the inter-ring space, which has a positive effect on the blow-by. At the same time, however, the values of this pressure decrease 
much more slowly during the exhaust stroke, which adversely affects the blow-up (Fig. 10).

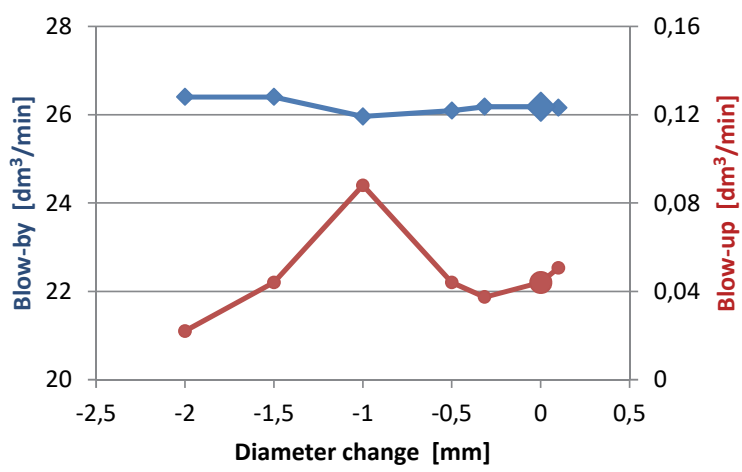

Fig. 8. Influence of piston diameter over the second compression ring $D 2 u$ on the blow-by and blow-up.

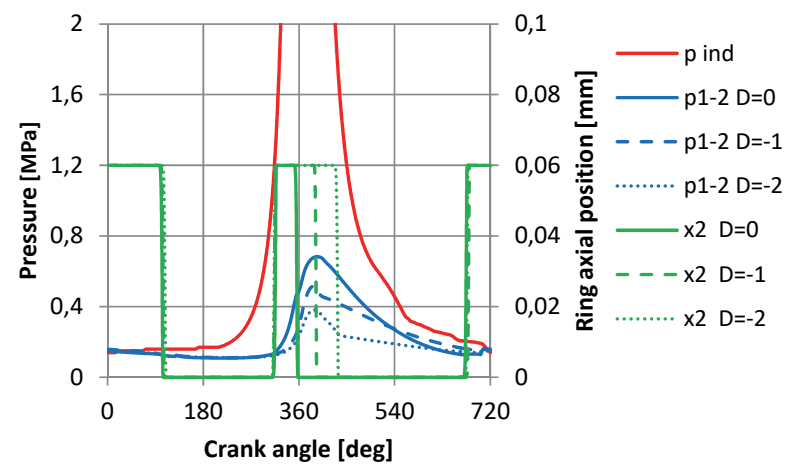

Fig. 9. Influence of piston diameter over the second compression ring $D 2 u$ on pressure in the inter-ring spaces and the axial displacement of the rings in the grooves.

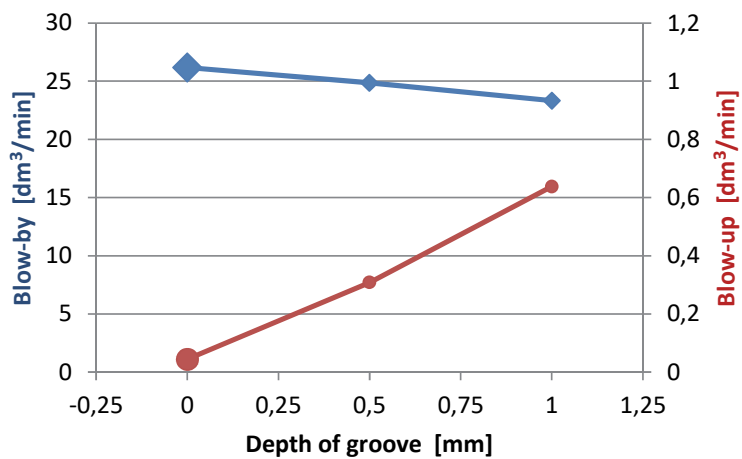

Fig. 10. The effect of the groove depth in the space between the first and second ring on the blow-by and blow-up flows.

\subsection{Combined impact of different dimensions on the PRC seal}

The influence of different combinations of piston and ring dimensions on blow-by and blow-up were analyzed. The analysis has shown that the greatest benefit, both from the point of view of blow-by and blow-up, can be achieved by reducing the clearances in the region of the first compression ring. Reducing the clearance in the lock of the second ring and increasing the diameter of the piston below it does not have such a large beneficial effect on blow-by, but at the same time adversely affects blow-up. Similarly, the use of an additional groove to increase the volume of the inter-ring space reduces blowby, but with a simultaneous increase in blow-up, with the negative impact of the groove on the blow-up being greater when the clearance in the lock of the second ring is smaller. The impact of different dimensional combinations on both blow-by and blow-down is shown in Figure 11. Unless otherwise stated in the figure or its caption, this means that for a given variant the given dimension is equal to the initial dimension (similarly in Fig. 12).

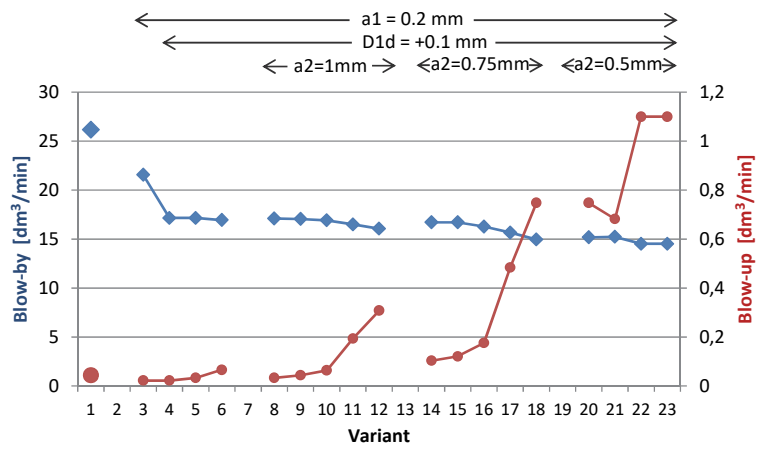

Fig. 11. Effect of different variants on the blow-by and blowup variant 1 - initial dimensions accepted by the manufacturer; $D 2 u=+0.1 \mathrm{~mm}$ for variants: $5-6,9-12,15-18$ and 21-22; $D 2 d=+0.1 \mathrm{~mm}$ for variants: $10,12,16,18,22$ and 23 ; $g=0.5 \mathrm{~mm}$ for variants: $6,11-12$ and $17-18$.

Reducing the clearance in the lock of the first ring by $0.05 \mathrm{~mm}$ and increasing the diameter of the piston below it by $0.1 \mathrm{~mm}$ would reduce blow-by and blow-up by more than a third. At the same time, reducing the clearance in the lock of the second ring and changing the dimensions of the piston in its surroundings allow a further reduction of blow-by, but at the expense of increased blow-up (Fig. 11). Unfortunately, such a reduction in the clearance in the lock of the first ring and an increase in the diameter of the piston under it could lead - at an unfavorable combination of elements and under very unfavorable operating conditions (heavy load, cold engine) - to elimination of the clearance altogether, causing engine damage. The introduction of such a change would probably require an increase in production rigor (tightening of the piston, ring and liner tolerances).

As a result of the above, in the next step an analysis was conducted to improve the performance of the seal without reducing the clearance of the first ring lock and increasing the diameter of the piston between the first and second rings. The analysis showed that there was a possibility of significant reduction in the blow-by, but at the expense of increased blow-up (Fig. 12). Reducing the clearance in the lock of the second ring to make it equal to the clearance of the first ring and increasing the diameter of the piston below it to dimensions that should not hinder the draining of oil, and making the groove in the inter-ring space would reduce the intensity of blowby by more than a third. Unfortunately, such changes would result in a massive increase in blow-up, to a numerical value close to that of the blow-by. In addition, 
such changes would adversely affect the axial displacement of the first ring in its groove. It should be emphasized that in this study the influence of only some structural parameters on the effect of the seal were analyzed. Other dimensions, in particular dimensions of the rings other than clearance in the locks and the dimensions of the piston ring grooves may also significantly affect the performance of the PRC seal.

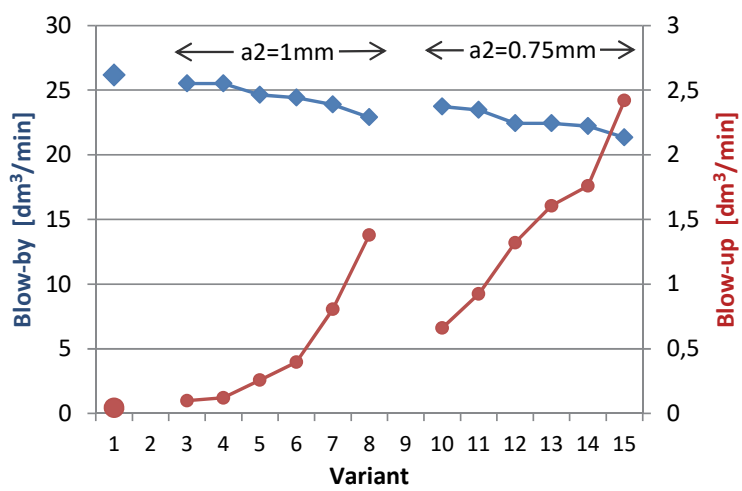

Fig. 12. Effect of different variants on the blow-by and blowup variant 1 - initial dimensions; $D 2 u=-0.2 \mathrm{~mm}$ for variants: $4,6,11$ and $13 ; D 2 d=+0.1 \mathrm{~mm}$ for variants: $5,6,8,12,13$ and $15 ; g=0.5 \mathrm{~mm}$ for variants: $7-8$ and $14-15$.

\section{Summary}

This paper presents the results of simulations of the impact of clearance in the compression ring locks and of selected dimensions of the ring belt of the piston on the functioning of the piston-ring-cylinder system. The study was made for a small automotive Diesel engine. The simulation results have shown that a significant reduction in the rate of gas flow from combustion chamber into the crankcase (without deteriorating other parameters characterizing the functioning of the ring pack) would require a reduction of the clearance in the first ring lock and the piston diameter under this ring. Unfortunately, such a change would require a tightening of engine component production tolerances.

Reducing the blow-by - without needing to increase the rigor of the production process - is possible by reducing the clearance in the lock of the second ring and the dimensions of the piston in its vicinity. However, this would be accompanied by an increased reverse flow of gas from the inter-ring space towards the combustion chamber. This could therefore lead to increased oil consumption and thereby higher concentrations of hydrocarbons and particulate matter in the exhaust gas.

The results of the research also showed that the dimensions of the rings and piston analyzed for the test engine had been optimized to minimize blow-up, at the expense of increased blow-by.

\section{References}

1. A. Ito, K. Tsuchihashi, M. Nakamura, SAE Technical Paper 2011-01-1402 (2011)
2. G. Koszalka, Eksploatacja i Niezawodnosc Maintenance and Reliability 48, 72-81 (2010)

3. G. Koszalka, Eksploatacja i niezawodnosc Maintenance and Reliability 51, 40-44 (2011)

4. P. Lyubarskyy, D. Bartel, Tribology International 104, 352-368 (2016)

5. J. Merkisz, J. Mizera, M. Bajerlein, L. Rymaniak, P. Maj, Experimental and Applied Mechanics 518, 102-107 (2014), DOI: 10.4028/www.scientific.net/AMM.518.102

6. J. Merkisz, J. Pielecha, W. Gis, WIT Transactions on Ecology and the Environment 120, 439-449 (2009), DOI: 10.2495/SDP090411

7. W. Serdecki, P. Krzymień, Combustion Engines 161, 53-63 (2015)

8. A. Usman, C.W. Park, Energy Conversion and Management 117, 115-131 (2016)

9. M.P. Veettil, F. Shi, SAE Technical Paper 2011-011406 (2011)

10. A. Wolff, Tribology Transactions 57, 653-667 (2014)

11. P. Wróblewski, A. Iskra, Combustion Engines 167, 38-52 (2016)

12. E. Yilmaz, T. Tian, V. Wong, J. Heywood, SAE Technical Paper 2004-01-2909 (2004)

13. A. Oliva, S. Held, Tribology International 101, 98109 (2016)

14. I. Pielecha, W. Cieslik, Journal of Thermal Analysis and Calorimetry 126, 815-827 (2016), DOI: 10.1007/s10973-016-5544-1

15. B. Thirouard, T. Tian, SAE Technical Paper 200301-1952 (2003)

16. P.J. Burnett, SAE Technical Paper 920089 (1992)

17. C. De Petris, V. Giglio, G. Police, SAE Technical Paper 961216 (1996)

18. G. Koszalka, A. Suchecki, Combustion Engines 154, 34-39 (2013)

19. G. Koszalka, M. Guzik, Polish Maritime Research 21, 66-78 (2014), DOI: 10.2478/pomr-2014-0043

20. S. Przesmitzki, T. Tian, SAE Technical Paper 200801-0794 (2008) 